\title{
Letter
}

\section{A Summary of EU National Statistical Reports of Animal Experiments in 2014-2016}

\author{
Katy Taylor and Laura Rego Alvarez \\ Cruelty Free International Trust, London, UK
}

\section{Introduction}

Directive 2010/63/EU of the European Parliament and of the Council of 22 September 2010 on the protection of animals used for scientific purposes (the Directive) requires that all EU member states submit - and then publish - statistics on their use of animals to the European Commission (EC) on an annual basis:

Article 54(2) "Member States shall collect and make publicly available, on an annual basis, statistical information on the use of animals in procedures, including information on the actual severity of the procedures and on the origin and species of non-human primates used in procedures. Member States shall submit that statistical information to the Commission by 10 November 2015 and every year thereafter."

In November 2012, revised requirements were introduced to increase the detail and scope of the information required and to establish a common format for reporting (EC Implementing Decision of 14 November 2012 establishing a common format for the submission of the information pursuant to Directive 2010/63/ EU of the European Parliament and of the Council on the protection of animals used for scientific purposes (2012/707/EU)) (the Implementing Decision). Changes from the previous reporting requirements included a change from reporting animals to reporting procedures (i.e., experiments), the severity of those procedures, more details on the origin of the animals and the types of procedures, especially those for regulatory purposes. 2014 was the first year for which member states had to submit and publish their annual statistics according to the new format. However, according to Article 57(2) of the Directive, the EC is not required to publish a summary based on these reports until November 10 , 2019 , and then every three years subsequently.

We believe that there is a public interest in knowing the extent of animal experimentation in Europe on a regular basis and so, rather than wait for the 2019 EC report, we collated the 2014 data available from EU member states and published it in ALTEX (Taylor and Rego, 2016). We found that two countries had not published their 2014 report yet and 21 countries were missing information from certain tables in the Implementing Decision. At a meeting of National Contact Points for the Directive in March 2017, the EC confirmed that the annual public reports should include the information required in the Implementing Decision. They had previously assisted member states with a suggested template. In order to further assist in the transparency of the reports, the website for the EC unit responsible for the Directive also began including the links to the public websites of member states containing their statistical reports from 2014 onwards $^{1}$.

In the interests of accelerating public awareness of the scale of animal use in experiments and in order to obtain a more up-todate figure, we used this resource to collate the national reports for 2016 (Tab. 1). This enabled us to provide a more accurate figure that can also be compared with 2014. All but Portugal have made their animal statistics for 2016 publicly available.

\section{Quality of the statistical reports}

While this is the third year of reporting under the new format, there still appear to be errors in the numbers reported as member states continue to adjust to the changes in the way that animals are counted (e.g., there are discrepancies in the number of procedures reported in the severity and purpose tables for Spain and Poland and some countries such as Greece are still using "animals" as the terminology rather than "procedures"). However, compared with 2014 , the quality of the statistical reports published by member states has improved. A total of 13 countries contained all the tables given in the Implementing Decision (compared to just five in 2014); these were Belgium, Croatia, Czech Republic, Denmark, Estonia, Finland, Germany, Hungary, Ireland, Lithuania, Slovakia, Sweden, and the UK. (Austria may also be complete, but it is hard to tell based on their reporting format, which is in the form of a database print out).

Bulgaria did not provide any data on procedures by "Purpose". Seven member states failed to include details of the research areas under "Basic research studies" or "Translational and applied

\footnotetext{
1 http://ec.europa.eu/environment/chemicals/lab_animals/member_states_stats_reports_en.htm
}

Received December 21, 2018; Accepted January 11, 2019; (c) The Authors, 2019.

ALTEX 36(2), 314-319. doi:10.14573/altex.1812211

Correspondence: Katy Taylor, PhD, European Coalition to End Animal Experiments; 16a Crane Grove, London, N7 8NN, UK (katy.taylor@crueltyfreeinternational.org)
This is an Open Access article distributed under the terms of the Creative Commons Attribution 4.0 International license (http://creativecommons.org/licenses/by/4.0/), which permits unrestricted use, distribution and reproduction in any medium, provided the original work is appropriately cited. 
research" (Bulgaria, France, Greece, Italy, Latvia, Netherlands, Romania, and Slovenia).

Five member states did not provide data on "Regulatory use and routine production by type" and any of the subsequent sub tables related to this (Bulgaria, Greece, Italy, Romania and Slovenia; Greece did not because they appear to not conduct these tests). A further four did not provide data on procedures by "Toxicity and other safety testing required by legislation" or by "Legislative requirements" (Cyprus, Luxembourg, Poland, and Spain; Luxembourg did not because they appear to not conduct these tests). A further three included these tables but not the sub tables detailing "Toxicity and other safety testing by test type" (France, Latvia, Netherlands). Bulgaria and Slovenia did not report the "Severity" of procedures while four member states (Bulgaria, Cyprus, Latvia, and Slovenia) did not provide data on the "Place of birth" of the animals. Cyprus, Romania, and Slovenia also did not provide the number of procedures in the "Purposes" table that related to "Maintenance of colonies of established genetically modified animals, not used in other procedures". These countries as well as Italy, Latvia, Luxembourg, Netherlands, and Poland also did not report the "Genetic status" of the animals used in procedures overall.

Tab. 1: Total number of procedures conducted on animals by each EU member state, 2014-2016

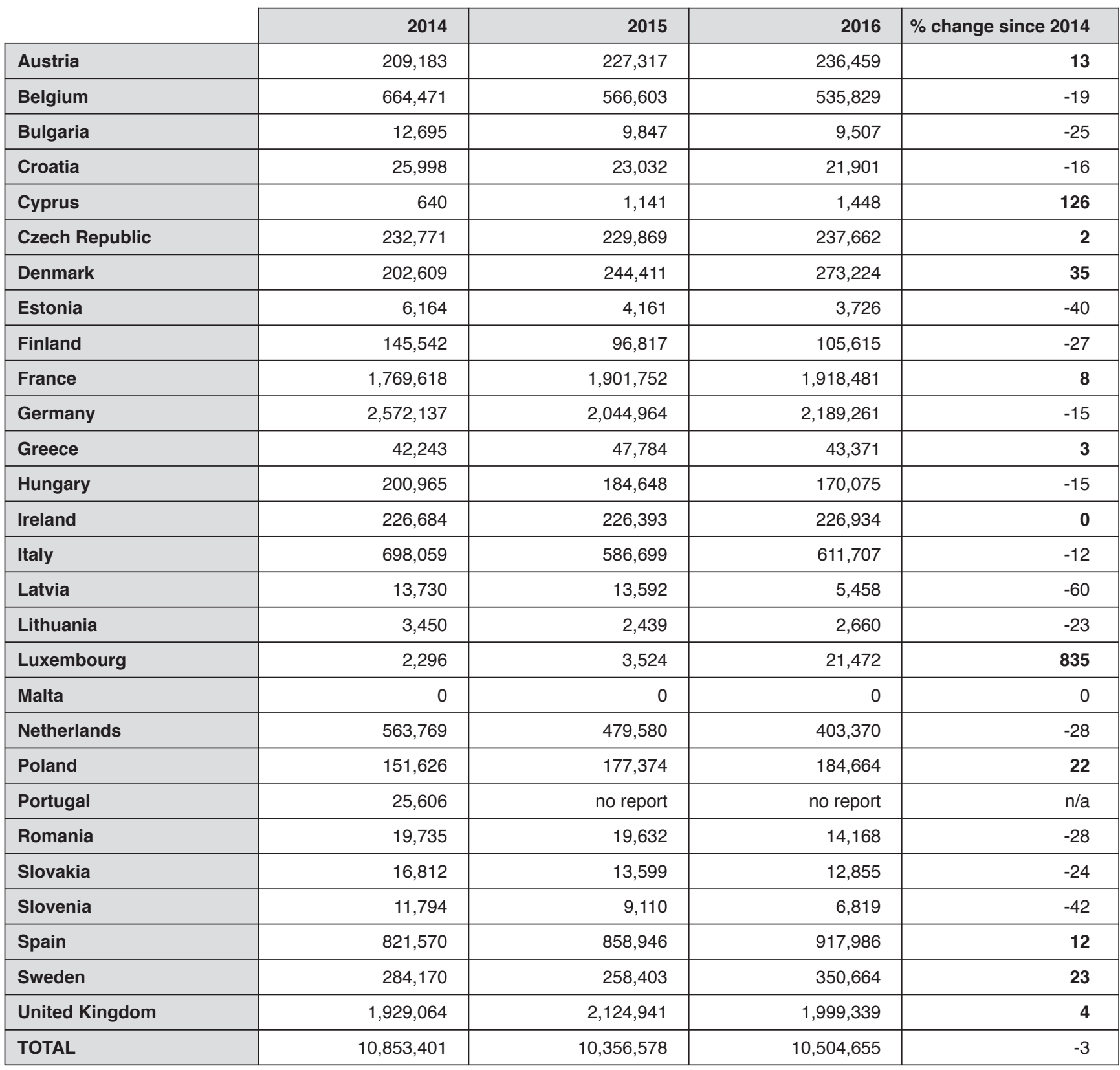

Note: percentage increases are highlighted in bold 
Sixteen member states published the results of at least one of the required tables by "Type of animal", usually by "Purpose" and/or by "Severity". Denmark, France, Germany, Netherlands, Sweden, and the UK provided most, if not all, tables by "Type of animal". Some countries also provided a narrative to the information.

Germany, Netherlands, Sweden, and the UK report additional uses of animals to those required in the Implementing Decision. These are animals killed for their tissues (Germany, Netherlands, and Sweden), animals used in "sub-threshold" or non-EU regulated procedures (Sweden and the UK), all animals used to maintain GM animals, i.e., normal animals and GM animals without a harmful mutation (the UK) and surplus animals bred but not used (Netherlands). The UK include the "sub-threshold" procedures within their report and these have had to be manually removed in our analysis so the figures are comparable to the Implementing Decision. According to their definition, "sub-threshold" is when a procedure was authorised under a project licence but did not actually cause suffering above the threshold of regulation, i.e., was less than the level of pain, suffering, distress, or lasting harm that is caused by inserting a hypodermic needle according to good veterinary practice. In Sweden, a large majority of the procedures in fish are for "test-fishing", which may include tagging, which is an identification procedure not considered a procedure under the Directive.

\section{Overall change in animal use}

Without Portugal, the total harmonised number of procedures in the EU in 2016 was 10.5 million, a slight decrease from 10.8 million in 2014 (Tab. 1). The 2014 total here differs to our previous report in that there we had included "sub-threshold" procedures reported by the UK previously (Taylor and Rego, 2016). A number of countries have also subsequently adjusted their 2014 reports to enable errors to be corrected.

Out of those users with more than 1 million procedures, the UK increased by $4 \%$ since 2014 , France increased by $8 \%$, and Germany reported $15 \%$ fewer procedures (Tab. 1). Germany is currently the biggest reported user of animals in the EU with 2.2 million procedures per year. The UK is the second highest user with 2.0 million (adjusted), and France third with 1.9 million procedures.

Out of those using fewer than 1 million animals but more than 100,000 animals, Belgium, Finland, Hungary, Italy, and the Netherlands reported an overall decrease since 2014, while Austria, the Czech Republic, Denmark, Poland, Spain, and Sweden reported an overall increase (Tab. 1). Ireland's use did not significantly change. The overall decrease since 2014 is therefore explained mostly by the decrease in procedures from Germany but also Italy and Belgium (both of which had conducted over 650,000 procedures in 2014).

There remain several countries (11 in 2016) that report relatively limited animal use of less than 100,000 procedures (Tab. 1). Fluctuations in their numbers can give rise to large percentage changes from 2014 but have little influence on the overall number for the EU. For example, Luxembourg and Cyprus both reported large increases of $835 \%$ and $126 \%$, respectively, since 2014 but

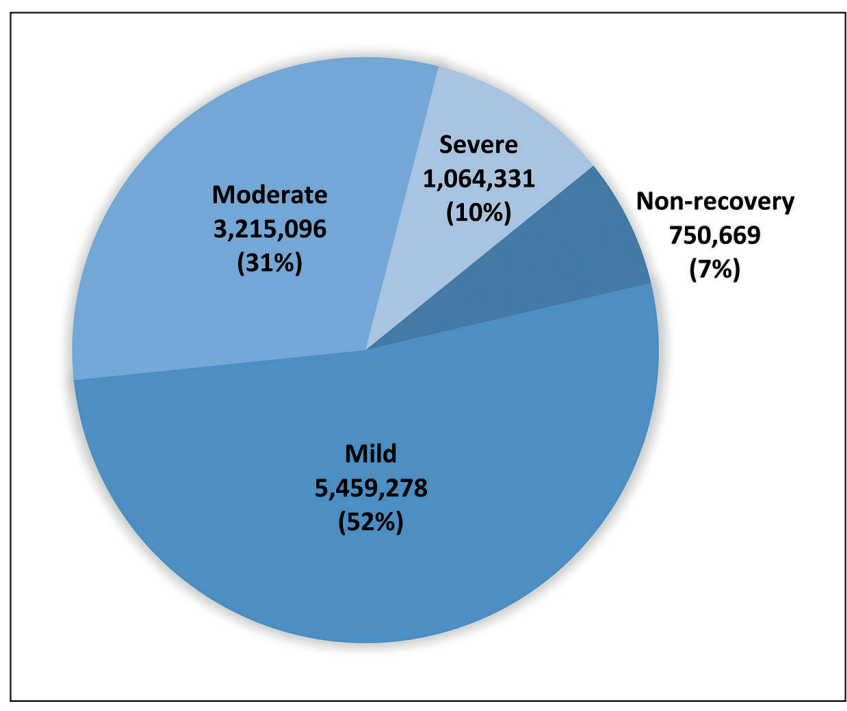

Fig. 1: Overall severity of procedures in the EU in 2016 from 25 reporting member states

the total number of procedures for each country has only risen to 21,472 and 1,448, respectively. Malta reported using no animals in 2014,2015 , or 2016 .

\section{Severity of experiments}

2014 was the first year for which member states had to report the actual severity of the procedures for each and every animal, as considered by the researcher doing the assessment. At the time, five countries failed to include this new requirement in their public reports but in 2016, all but two member states provided information on severity. The categories are non-recovery (procedure done entirely under general anaesthesia and the animal does not regain consciousness), mild, moderate, and severe.

Using severe suffering as an example, there is wide variation in the reports of suffering. Most countries report severe suffering in less than $10 \%$ of the procedures. However, Italy (11\%), Estonia (11\%), France (17\%), Belgium (18\%), Czech Republic (21\%), Poland (23\%), and Ireland (29\%) reported higher levels of severe suffering. Out of the total from 25 member states that included information on severity, $7 \%$ were classified as non-recovery, $52 \%$ as mild, $31 \%$ as moderate, and $10 \%$ as severe (see Fig. 1).

\section{Trends in dog and non-human primate use}

A total of 23,464 procedures conducted in 2016 were on dogs (decrease of $2 \%$ from 23,847 procedures in 2014) (see Fig. 2) across 17 member states. The UK is the only country that specifies how many procedures involved beagles ( $94 \%$ of UK dog experiments) or "other dogs". Ten member states did not use dogs in 2016; Croatia, Cyprus, Estonia, Latvia, Lithuania, Luxembourg, Romania, Slovakia, and Slovenia. Six countries conducted more than 1,000 procedures on dogs in 2016 (UK, France, Germany, Finland, Bel- 


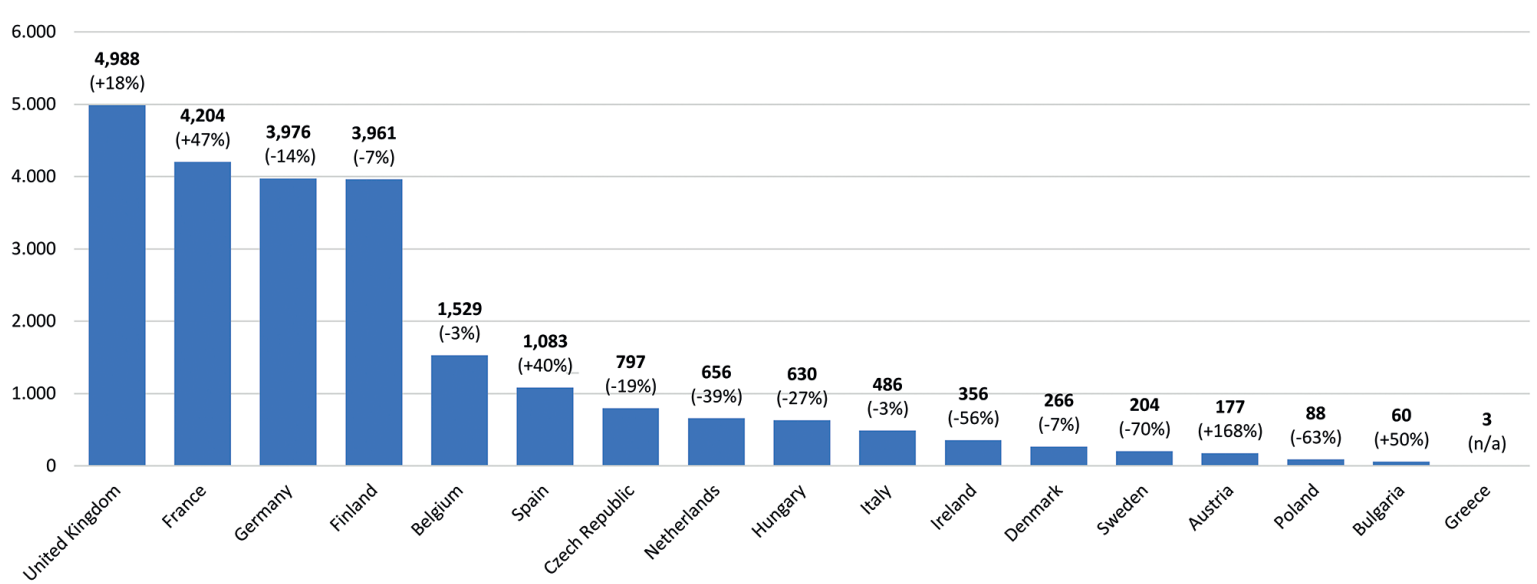

Fig. 2: Number of procedures on dogs by each member state using dogs with percentage change from 2014

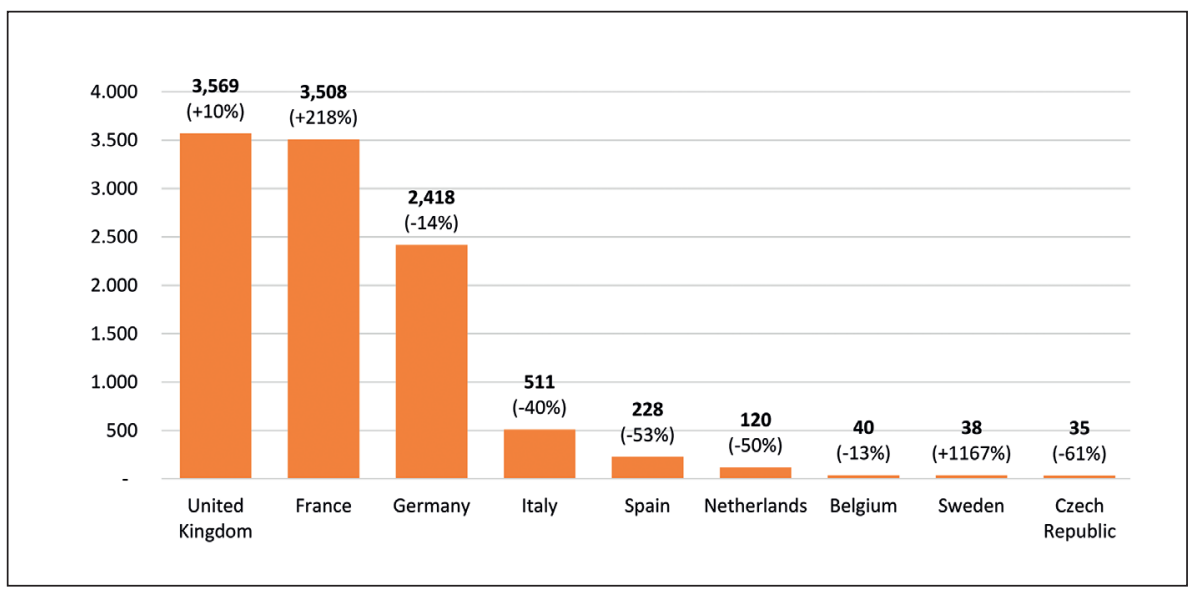

Fig. 3: Number of procedures on nonhuman primates by each member state using non-human primates, with percentage change from 2014

gium, and Spain) with the UK reporting the greatest number of procedures $(4,988)$. France is the second highest user with 4,204 and Germany third with 3,976 experiments. Finland appears to report procedures that are blood sampling of pet dogs, which explains the majority of their dog use. Increases in dog use were reported by Austria (168\%), Bulgaria (50\%), France (47\%), Spain (40\%), and the United Kingdom (18\%). Greece did not use any dogs in 2014 but reported dog use in 2016 ( 3 procedures). Decreases in dog use from 2014 were reported by all other member states.

10,467 procedures were conducted on non-human primates, an increase of $18 \%$ from 8,895 in 2014 , across nine member states (Belgium, Czech Republic, France, Germany, Italy, the Netherlands, Spain, Sweden, and the UK) (see Fig. 3). Of these procedures, 9,798 involved cynomolgous or rhesus macaques (94\%). Baboons were used in France (92 procedures) and Germany ( 8 procedures). France and Germany also used vervet monkeys (23 and 18 procedures, respectively) and prosimians ( 1 and 117 procedures, respectively). France was the only member state to use squirrel monkeys (8 procedures). Five member states reported the use of marmosets and tamarins: the UK (197 procedures), Germany (113 procedures), France (41 procedures), the Netherlands (16 proceedures, and Italy ( 9 procedures). The UK remains the high- est reported user of non-human primates with 3,569 procedures. France is the second highest user with 3,508 and Germany third with 2,418 procedures. Increases in non-human primate use were reported by France (218\% from 1,103 procedures in 2014 to 3,508 in 2016$)$, Sweden $(1,167 \%$ from 3 procedures in 2014 to 38 in $2016)$ and the UK ( $10 \%$ from 3,246 procedures in 2014 to 3,569 in 2016). Decreases in non-human primate use were reported by all other member states.

\section{Trends in general purposes}

Out of the total number of procedures conducted by EU member states, $47 \%$ were for basic research purposes, $21 \%$ were for applied research purposes and $25 \%$ were for regulatory purposes. Nearly $4 \%$ were for the maintenance of GM animals. The remaining 3\% were for "other purposes" including 161,629 procedures conducted for higher education or training (see Fig. 4).

Users of fewer animals were more likely to report proportionately higher basic research procedures, such as Croatia (88\%), Estonia (93\%), Greece (86\%), Lithuania (83\%), Luxembourg $(98 \%)$, and Slovakia (71\%). However, the larger users Sweden and 
Poland also reported high proportions of basic research procedures ( $81 \%$ and $77 \%$, respectively). Only two member states (Ireland and Slovenia) reported that over $50 \%$ of procedures were for regulatory purposes ( $75 \%$ and $66 \%$, respectively). A significant proportion of the procedures in Ireland is for botulinum toxin batch tests for regulatory purposes (see Taylor et al., 2019). Latvia and Denmark reported that over $50 \%$ of procedures were for applied research purposes (90\% and 51\%, respectively). Romania and the Czech Republic reported the highest proportion of education and training use ( $11 \%$ and $7 \%$, respectively).

\section{Trends in regulatory tests with alternatives}

In 2014, only six member states completed the "Regulatory use and routine production by test type" table and sub tables (Taylor and Rego, 2016). This improved significantly in 2016 and the numbers of procedures for 19 member states provide enough information to determine the use of animals in some key regulatory tests (i.e., those with validated alternatives).

In the 19 reporting countries, there were a total of 1,552 skin irritation tests, 551 eye irritation tests and 21,891 skin sensitisation

Tab. 2: Numbers of skin irritation, eye irritation, skin sensitisation, batch potency, and pyrogenicity procedures on animals in 2016 in reporting member states

Significant increases from 2014 are noted in bold

\begin{tabular}{|c|c|c|c|c|c|}
\hline & \multirow{2}{*}{ Skin irritation } & \multirow{2}{*}{ Eye irritation } & \multirow{2}{*}{ Skin sensitisation } & \multirow{2}{*}{ Batch potency } & \multirow{2}{*}{ Pyrogenicity } \\
\hline & & & & & \\
\hline Austria & 0 & 0 & 0 & 17,604 & 13,157 \\
\hline Belgium & 0 & 0 & 0 & 6,345 & 0 \\
\hline Bulgaria & No report & No report & No report & No report & No report \\
\hline Croatia & 0 & 0 & 0 & 194 & 67 \\
\hline Cyprus & No report & No report & No report & No report & No report \\
\hline Czech Republic & 0 & 3 & 570 & 15,636 & 51 \\
\hline Denmark & 35 & 0 & 80 & 5,486 & 0 \\
\hline Estonia & 0 & 0 & 0 & 0 & 0 \\
\hline Finland & 0 & 0 & 0 & 0 & 0 \\
\hline France & No report & No report & No report & No report & No report \\
\hline Germany & 758 & 200 & 8,604 & 155,904 & 347 \\
\hline Greece & 0 & 0 & 0 & 0 & 0 \\
\hline Hungary & 184 & 131 & 5,438 & 13,252 & 646 \\
\hline Ireland & 0 & 0 & 0 & 167,549 & 506 \\
\hline Italy & No report & No report & No report & No report & No report \\
\hline Latvia & No report & No report & No report & No report & No report \\
\hline Lithuania & 15 & 0 & 0 & 0 & 0 \\
\hline Luxembourg & 0 & 0 & 0 & 0 & 0 \\
\hline Malta & 0 & 0 & 0 & 0 & 0 \\
\hline Netherlands & No report & No report & No report & No report & No report \\
\hline Poland & 195 & 50 & 1,187 & 10,585 & 125 \\
\hline Portugal & No report & No report & No report & No report & No report \\
\hline Romania & No report & No report & No report & No report & No report \\
\hline Slovakia & 0 & 0 & 632 & 235 & 0 \\
\hline Slovenia & No report & No report & No report & No report & No report \\
\hline Spain & 99 & 39 & 794 & 39,956 & 9,878 \\
\hline Sweden & 0 & 0 & 0 & 1,012 & 0 \\
\hline United Kingdom & 266 & 128 & 4,586 & 145,190 & 2,472 \\
\hline TOTAL & 1,552 & 551 & 21,891 & 578,948 & 27,249 \\
\hline
\end{tabular}




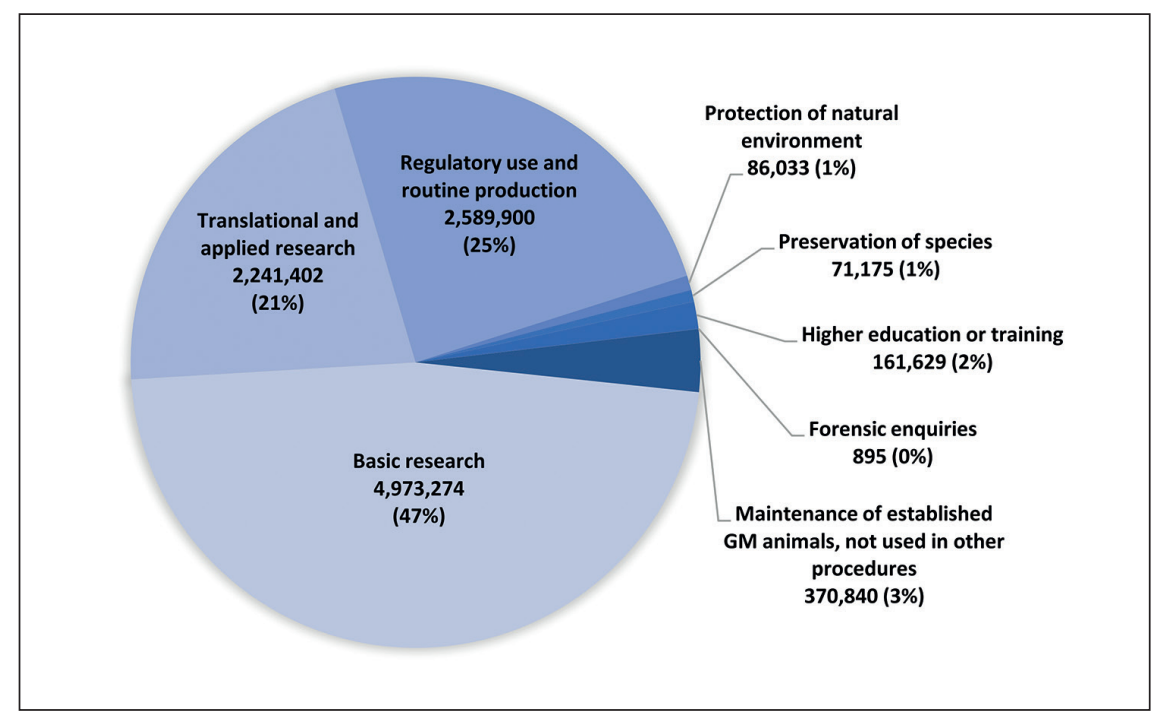

Fig. 4: Overall purpose of procedures in the EU in 2016 from 26 reporting member states

tests on live animals in 2016 (see Tab. 2). There were also 27,249 pyrogenicity tests and 578,948 batch potency tests (a proportion of which is likely to include botulinum toxin batch tests (see Taylor et al., 2019)).

For the six countries where a comparison between 2014 and 2016 was possible (data not shown), Spain and Hungary both reported increases in the number of skin irritation and eye irritation tests. Slovakia and Hungary did not conduct any skin sensitisation tests in 2014 but each reported 632 and 5,438 tests in 2016, respectively. Increases in batch potency tests were reported by Denmark (from 2,897 to 5,486), Spain (from 20,443 to 39,956), and the UK (from 16,154 to 145,190, although this might be erroneous reporting). Austria (from 6,897 to 13,157 procedures) and Spain (from 9,595 to 9,878 procedures) reported increases in pyrogenicity testing.

\section{Conclusion}

The annual statistics are an important source of information on the uses of animals in each member state and, when collated, can give a picture of animal use across the EU. The enhancement to the reporting requirements outlined in the Implementing Decision was intended to increase the transparency of animal testing required under Recital 4 and Article 54 of the Directive. Significant improvements have been made in the quality of the publicly available statistical reports since 2014. However, 14 member states $(50 \%)$ are still missing some of the information required by the Implementing Decision. Details of the research areas under "Basic research studies" or "Translational and applied research" were missing from seven $(25 \%)$ member states, information on "Legislative requirements" from nine (32\%) and "Toxicity and other safety testing by test type" from eight (29\%). The reports are meant to include information that can be used to help policymakers monitor the uptake of alternatives and to help prioritise investments in the $3 \mathrm{Rs}$. It is therefore imperative that both member states and the EC are tasked with urgently improving the consistency, quality and completeness of their statistical reports. It is possible that some countries are missing this information because they do not do these types of procedures. Nonetheless it is important that this is stated.

In total it appears that over 10.5 million experiments were concluded in 2016 across the EU. Comparison with comparable data from 2014 suggests this represents a small decrease from 2014. The latest EC summary of the member states reports indicated that 11.5 million animals were used in experiments in 2011 (EC, 2013). Given the change in reporting requirements and the difficulties member states have experienced in changing reporting systems, most notably from reporting animals to reporting procedures, it is difficult to know whether these more recent figures constitute a real decrease in use since 2011. Hopefully, a more detailed analysis will be available from the EC by the end of 2019. In the meantime, our analysis should be seen as a warning that animal experiments remain at a significant and relatively static level in the EU. In our opinion, urgent attention is needed to turn the direction more meaningfully downward. Of particular public concern will be the numbers of dogs $(23,464$ procedures) and non-human primates (10,467 procedures) still being used in the EU.

\section{References}

EC - European Commission (2013). Commission Staff Working Paper - Report on the Statistics on the Number of Animals used for Experimental and other Scientific Purposes in the Member States of the European Union in the year 2011, SWD 497 final. https://eur-lex.europa.eu/legal-content/EN/ TXT/?uri=CELEX:52013SC0497

Taylor, K. and Rego Alvarez, L. (2016). Letter: EU statistics on animal experiments for 2016. ALTEX 33, 465-468. doi:10.14573/altex.1609291

Taylor, K., Gericke, C. and Rego Alvarez, L. (2019). Botulinum toxin testing on animals is still a Europe-wide issue. ALTEX 36, 81-90. doi:10.14573/altex.1807101 